\title{
Revealing Causal Factors Influencing Sustainable and Safe Navigation in Central Europe
}

\author{
Andrea Maternová ${ }^{1, *(\mathbb{D}}$, Matúš Materna ${ }^{2}\left(\mathbb{D}\right.$ and Andrej Dávid $^{1}$ (D) \\ 1 Department of Water Transport, Faculty of Operation and Economics of Transport and Communications, \\ University of Zilina, Univerzitna 1, 02601 Zilina, Slovakia; andrej.david@fpedas.uniza.sk \\ 2 Air Transport Department, Faculty of Operation and Economics of Transport and Communications, \\ University of Zilina, Univerzitna 1, 02601 Zilina, Slovakia; matus.materna@fpedas.uniza.sk \\ * Correspondence: andrea.maternova@fpedas.uniza.sk; Tel.: +421-41-513-3552
}

check for updates

Citation: Maternová, A.; Materna, M.; Dávid, A. Revealing Causal Factors Influencing Sustainable and Safe Navigation in Central Europe. Sustainability 2022, 14, 2231. https://doi.org/10.3390/su14042231

Academic Editor: Stergios

Aristoteles Mitoulis

Received: 11 January 2022

Accepted: 9 February 2022

Published: 16 February 2022

Publisher's Note: MDPI stays neutral with regard to jurisdictional claims in published maps and institutional affiliations.

Copyright: (c) 2022 by the authors. Licensee MDPI, Basel, Switzerland. This article is an open access article distributed under the terms and conditions of the Creative Commons Attribution (CC BY) license (https:// creativecommons.org/licenses/by/ $4.0 /)$.

\begin{abstract}
Even though inland navigation represents the safest transport mode, consequences of accidents are significantly higher, because of the larger quantities of cargo transported, compared with the conventional means of transport. Accidents in inland waterways are a regular phenomenon throughout the year, causing deaths, injuries, and monetary loss, and endangering the environment. At present, comprehensive research on inland navigation accidents including their causes and consequences is lacking. For this purpose, data about real accidents on the Danube River were collected and analysed in this study. This paper provides a comprehensive study of the hazards (causal factors) and resulting risks in inland waterway transport. Two methods were applied to fulfil the aim - a cause and effect diagram, used for hazard identification, and a risk matrix, used for risk assessment. The analysis confirmed the presence of recurring hazards, resulting mainly from human behaviour. This study can be used for the methodology and design of preventive measures to ensure safe inland navigation.
\end{abstract}

Keywords: inland navigation; water transport; waterways; Danube; safety

\section{Introduction}

Inland water transport plays a crucial role for the transport of goods and passengers in Europe. More than 37,000 kilometres of waterways connect hundreds of cities and industrial regions. The Danube, the longest waterway in the EU, serves as the backbone of this region, ensuring better transport connections and economic growth. Since the opening of the Main-Danube Canal in 1992, Danube has been connected with Western European waterways through the Main River, the right-side tributary of the Rhine River [1]. The Danube River is an integral part of the Trans-European Transport Network (TEN-T) [2]. Via this complex canal network, the Danube connects the port of Rotterdam in the Netherlands with the Black Sea. In addition to its global importance, the Danube has also been significant for the development of the countries through which it flows.

The strengths of Danube navigation lie in the river's ability to carry large quantities of goods per vessel unit, its environmental friendliness, and its low transport costs [3]. Moreover, water transport represents the cheapest and the most ecologically friendly means of transport [4]. On the other hand, the Danube's weaknesses lie in its dependence on current fairway and meteorological conditions. The speed of inland navigation together with the Danube network's density represents another disadvantage of inland navigation. If compared with other modes of transport, Danube navigation provides the lowest specific energy consumption and the lowest external costs of any modes of transport on land. In addition, it requires comparably lower investments in maintaining and expanding its infrastructure.

A prerequisite for the utilisation of the undisputed potential of inland navigation is the removal of existing infrastructure bottlenecks and weak spots. For this purpose, 
several tools of risk management are used. Risk management is one of the key issues when planning safe inland navigation. Examining risks by means of a semi-quantitative risk assessment method allows for focusing strictly on operational risks that result from the transport process. There are plenty of risky activities when handling and carrying cargo. In order to identify activities that lead to accidents in inland navigation, it is necessary to:

(1) Examine transportation and supply chains as a complex of loading procedures, transportation, freight forwarding, and unloading processes (the topic of supply chains is discussed in detail in the chapter on dangerous goods);

(2) Identify operational risks from the perspective of the main parties involved;

(3) Assess risks in the combination of risk consequences and their probability.

\section{Literature Overview}

At present, in the literature, there is a lack of publications dealing with the safety of freight transport on the Danube. Authors of scientific publications dealing with safe Danube shipping focus mainly on environmental safety (e.g., investigation of levels of organic pollutants in different parts of the Danube, the impact of hydropower on the flood control safety of some Danube regions, reducing fish populations). Moreover, the scientific literature focuses mainly on the Lower Danube.

On the other hand, there is a wealth of scientific literature on navigation safety, but such publications do not include European waterways. For example, Zhang et al. (2013) proposed an accident approach for congestion risk assessment of inland navigation. The main outcomes of the study can be used to effectively diagnose and predict the congestion risks of inland waterways in general and on the Yangtze River [4]. Vidan et al. (2013) provided new measures for traffic volume boosts. The authors expect that the implementation of new measures can ensure optimal planning of navigation and better awareness of potential threats on waterways [5]. Galieriková and Sosedová (2016) pointed to the importance of inland water transport and emphasised the need to shift more freight volume to this environmentally friendly transport mode [6].

Another significant study by Uddin et al. (2017) identified crucial threats endangering safe and efficient inland navigation [7]. This study contains an analysis of shipping accidents on Bangladesh's waterways, and the authors provide comprehensive guidance for a safer waterway transportation system in Bangladesh. Sun et al. (2017) developed an evaluation model of safety risks in inland navigation in Shanghai. Based on an analysis of Shanghai's waterway safety, a comprehensive analysis according to four aspects (environment, hardware, software, and liveware) was provided [8].

Yu et al. (2021) examined factors affecting safe navigation [9]. In this publication, three different risk levels of potential collisions were identified. Moreover, management strategies were provided to avoid ship collisions and reduce potential pollution. Another significant publication about the safety of navigation is represented by the study of Liu et al. (2021) dealing with a comprehensive suggestion for maritime administrators and mariners based on the identification of accident factors. The research findings provide guidance to support risk prevention and advance a safe system in coastal waters [10]. Yan et al. (2021) provided a comprehensive study on river current and flow directions influencing safe navigation. Moreover, a navigation risk model was established based on model test results from the Beijing River, the upper reaches of the Yangtze River, and the upper reaches of the Xiangjiang River [11].

If we move from scientific publications to the outputs of various projects and strategies, it is important to point out the work of Via Donau. Via Donau is one of the leading international waterway operators in the Danube region; it has issued many publications dealing with the safety and efficiency of Danube navigation. The European Commission, in collaboration with Via Donau, published a major publication: "Study on Rhine-Danube TEN-T Core Network Corridor" [12,13]. Its main objective is to enhance the strategies for increasing the efficiency of inland waterway transportation and improving its competitiveness. Moreover, the issue of safety is also analysed and described in this publication. 
Via Donau, a modern waterway management company, executes sovereign functions on behalf of the Austrian government in the field of waterway and inland navigation. In addition to the tasks of federal waterway administration and transport development, Via Donau publishes significant materials such as the Manual on Danube Navigation, which captures Danube navigation with all its achievements, developments, and services and also identifies the potential for Danube navigation which have yet to be used and promoted. The manual is addressed to practitioners in inland waterway transport and to anyone interested in navigation. It also serves as a textbook for professional training in this sector [3].

\section{Materials and Methods}

Currently, about 40 hazard identification methods exist. Methods greatly depend on the experience of persons carrying out the study (in this case, experts from the Division of IWT-Transport Authority Slovakia) and authors (academics from the Department of Water and Air Transport-experts on risks in the field of transport). The initial techniques used for fulfilling the Ishikawa diagram were techniques started with unstructured "brainstorming" and finished with more structured "what if" analysis.

The process of hazard investigation was not limited to already known hazards from the past (according to accident data), but the authors also considered what may happen. There are several significant tools for hazard identification, some of which are more formalised, such as highly structured hazard and operability (HAZOP) analysis and failure mode and effect analysis (FMEA). These tools identify hazardous events and determine causes and consequences. HAZOP was developed for the chemical industry, and FMEA was primarily developed for the automobile industry. Even though these tools are currently used in various sectors, a C\&E diagram was used for the categorisation of each hazard, for a better understanding of consequences and an easier process of risk assessment.

A comprehensive database is required to perform accident-related research activities. The waterway accident data were collected from the Transport Authority-Division of Inland Navigation of Slovak Republic. First, all accident data for the past decades were collected-the database contains about 185 accidents that occurred on the Slovak part of the Danube River. The database contains data about both the cargo and passenger vessels.

The next step was the data analysis, based on the cause and effect diagram. Causal factors (hazards) were divided into 6 main categories (Table 4 shows the database structure (all causal factors were identified when an accident occurred)).

Subsequently, causal factors that contributed to the risk were identified. In the last step, the risks were assessed using a risk matrix.

\subsection{The Cause and Effect Diagram (Fishbone Diagram)}

A cause and effect diagram, also called a fishbone or Ishikawa diagram, is a method that shows potential causes of specific events. This tool is used for displaying relationships between an effect and its potential causes. The composition of the diagram looks like a fishbone. These diagrams are often designed from right to left, with each big "bone" of the skeleton branching out to include small bones with more details. This method uses a diagram-based approach for identifying all possible causes of a problem, threat, or risk [14].

Root cause analysis is intended to show key relationships among various variables. The causes are often revealed through a brainstorming method, and then the causes are categorised into the groups on the main branches of the fishbone. To help structure the approach, the groups are often selected from common models: the 4Ss model, used in the service industries; the $6 \mathrm{Ms}$ model, used in manufacturing (also the most common framework for root cause analysis); and the 8Ss model, used in product marketing [15]. For the purpose of this research, the $6 \mathrm{Ms}$ model was chosen. Causes were categorised into 6 groups to identify the sources of variation:

- Manpower (people/personnel): any person involved in the process;

- Methods: the performance of the process and its specific conditions, such as rules, regulations, laws, and procedures; 
- Machines: technologies, computers, equipment, tools required to accomplish the process;

- Materials: components, raw materials and consumables, labelling, storage, physical properties;

- Mother nature (environment): parameters such as the time, temperature, location, and culture in which the process operates;

- Measurement: inspections and physical measurements, whether manual or automatic.

\subsection{Risk Matrix}

Risk analysis is a complex tool requiring knowledge, expertise, and experience in the research area. Academics and experts together ensure a complex investigation of shipping accidents and risk assessment. The process of risk assessment must be as comprehensive, transparent, and consistent as possible. Currently, there is no universally agreed risk analysis method applied in each sector. The methods are selected based on the perceived relevance, available resources, or utility. For example, a method adopted in industry may not be suitable in the field of natural hazards.

There are mainly three types of methods used for risk assessment: qualitative methods, semi-quantitative methods, and quantitative methods. Qualitative methods are based only on the compliance assessment. Semi-quantitative methods apply to the categorisation of those components, and the final risk score is achieved using different methods. Quantitative methods are based on the risk measure assessment within the QRA [16]. In this paper, the semi-quantitative approach was used for the assessment of risk in Danube navigation, and a risk matrix, as a tool of the semi-quantitative approach, was used for the risk evaluation and assessment.

A risk matrix, as a tool of semi-quantitative risk assessment, represents a combination of two dimensions of risk-severity and likelihood-which allows an immediate and clear comparison of different risks [17]. Severity can be considered for any negative consequence such as a fire, an explosion, the release of dangerous substances, the impact of natural hazards, environmental damage, property damage, injuries, and fatalities. A severity scale is graded from negligible to catastrophic and can be estimated (or calculated). The levels of severity of a normal risk matrix are usually $4-6$, covering this range with a similar number of probability scales. There is no universally adopted set of descriptions for these levels, so a logical selection should be based on the purpose of the risk assessment being carried out. The example shown in the table below is used for a risk assessment by a shipping company, including effects on people, property, and the environment. Therefore, the severity scale can be defined as:

- Negligible: small consequences, short restriction on navigation;

- Minor: minor injury quick recovery, traffic restrictions, delays in delivery time;

- Moderate: serious injuries (disabling), damage to the vessel, damage to cargo, financial losses;

- Major: single fatality, vessel crash, extensive damage to the vessel, large financial losses, most of the equipment destroyed, smaller leakage of harmful substances;

- Catastrophic: fatalities, large environmental accidents, destruction of the vessel, irreparable losses.

Similarly, the likelihood scale is defined as:

- Rare: almost impossible occurrence of risk;

- Unlikely: very unlikely (unusual occurrence);

- Low: possible but unlikely occurrence;

- Likely: probability of occasional risk (irregular occurrence);

- High: probability of frequent occurrence (regular occurrence).

When applying the matrix, a rank may be provided for risks by categorising them into tolerable (in green), intermediate (in yellow and orange), or intolerable (in red) levels. A risk with severe consequences "likely" to occur would absolutely fall into the red zone 
(intolerable). A risk posing minor consequences would be intermediate, and "very rare" in likelihood would be categorised into the tolerable level. For risks which appear in the intolerable level, the decision must be carried out concerning the next steps (see Table 1).

Table 1. Levels of risk according to consequences and likelihood.

\begin{tabular}{cccccc}
\hline \multirow{2}{*}{ LIKELIHOOD } & \multicolumn{4}{c}{ CONSEQUENCES } \\
\cline { 2 - 6 } & Negligible & Minor & Moderate & Major & Catastrophic \\
\hline High & $\mathrm{M}$ & $\mathrm{H}$ & $\mathrm{H}$ & $\mathrm{E}$ & $\mathrm{E}$ \\
Likely & $\mathrm{M}$ & $\mathrm{M}$ & $\mathrm{H}$ & $\mathrm{H}$ & $\mathrm{E}$ \\
Low & $\mathrm{L}$ & $\mathrm{M}$ & $\mathrm{M}$ & $\mathrm{H}$ & $\mathrm{E}$ \\
Unlikely & $\mathrm{L}$ & $\mathrm{M}$ & $\mathrm{M}$ & $\mathrm{M}$ & $\mathrm{H}$ \\
Rare & $\mathrm{L}$ & $\mathrm{L}$ & $\mathrm{M}$ & $\mathrm{M}$ & $\mathrm{H}$ \\
\hline
\end{tabular}

Sources: Compiled by authors according [16].

Sometimes, numerical values are applied on the likelihood and/or severity axes of the matrix. This type of matrix is called a calibrated matrix. The following matrix (Table 2) shows the calibrated risks, according to the likelihood and frequency of accuracy of incidents.

Table 2. A calibrated risk matrix.

\begin{tabular}{|c|c|c|c|c|c|c|}
\hline \multicolumn{2}{|c|}{ FREQUENCY/LIKELIHOOD } & \multirow{2}{*}{$\begin{array}{c}\begin{array}{c}\text { Short Restriction } \\
\text { of Navigation }\end{array} \\
\text { broadly acceptable }\end{array}$} & \multirow{2}{*}{$\begin{array}{c}\begin{array}{c}\text { Minor Injury, Delay } \\
\text { in Delivery Time }\end{array} \\
\text { tolerable }\end{array}$} & \multirow{2}{*}{$\begin{array}{c}\text { Serious Injuries, } \\
\text { Vessel/Cargo } \\
\text { Damage } \\
\text { intolerable }\end{array}$} & \multirow{2}{*}{$\begin{array}{c}\text { Single Fatal- } \\
\text { ity/Financial } \\
\text { Losses } \\
\text { intolerable }\end{array}$} & \multirow{2}{*}{$\begin{array}{c}\text { Fatalities, Environ. } \\
\text { Accident } \\
\text { intolerable }\end{array}$} \\
\hline Likely & $>10^{-2} / \mathrm{yr}$ & & & & & \\
\hline Low & $>10^{-4} / \mathrm{yr}$ but $<10^{-2} / \mathrm{yr}$ & broadly acceptable & tolerable & intolerable & intolerable & intolerable \\
\hline Unlikely & $>10^{-6} / \mathrm{yr}$ but $<10^{-4} / \mathrm{yr}$ & broadly acceptable & tolerable & tolerable & tolerable & intolerable \\
\hline Rare & $>10^{-8} / \mathrm{yr}$ but $<10^{-6} / \mathrm{yr}$ & broadly acceptable & broadly acceptable & tolerable & tolerable & tolerable \\
\hline
\end{tabular}

Usually, an assessment of both severity and frequency is highly subjective and thus can considerably differ, even when produced by two people with similar experiences. For this reason, each step contributing to the creation of the risk matrix was consulted with experts in the field of water transport (employees of the Transport Authority-Division of Inland Navigation, and river firefighters).

\section{Results}

The number of IWT accidents remains high. This trend is influenced by the number of vessels transporting passengers and cargo on the Danube River. Between 2010 and 2015, the number of accidents oscillated about the number 10 (See Table 3). In this period, a higher number of fatalities and injuries were reported. There has been a significant increase in shipping accidents that occurred on the Slovak part of the Danube since 2015. In this period, there have been more fatalities reported-the higher number influenced by the higher demand for transportation of goods and passengers. About $80 \%$ of the total amount of shipping accidents occurred because of the human factor (mainly fatigue, alcohol, and negligence). The remaining $20 \%$ is covered by vis major and bad meteorological and hydrological conditions.

\subsection{Cause and Effect Diagram}

As mentioned, there are many elements affecting the process of inland navigation. These elements can support sustainable and safe navigation, or, conversely, they can contribute to the possible occurrence of risks and accidents. Using the cause and effect diagram, the main causal factors influencing safe navigation were identified (see Figure 1). 
Table 3. Shipping accidents on the Danube for the last 20 years.

\begin{tabular}{ccccc}
\hline Year & \multicolumn{2}{c}{ Number of Accidents } & \multicolumn{2}{c}{ Consequence } \\
\hline & Cargo Vessel & Passenger Vessel & Injury & Death \\
2010 & 4 & 5 & 1 & 2 \\
2011 & 4 & 6 & 2 & \\
2013 & 2 & 4 & 1 & \\
2014 & 6 & 3 & 1 & 2 \\
2015 & 7 & 4 & 2 & 1 \\
2016 & 4 & 10 & 2 & 1 \\
2017 & 10 & 9 & 3 & 3 \\
2018 & 9 & 7 & 4 & \\
2019 & 7 & 12 & 2 & \\
2020 Q1 & 5 & 11 & & \\
\hline
\end{tabular}

Source: Compiled by authors according to data from the Transport Authority (Division of IWT).

The Ishikawa diagram was created based on the brainstorming of the authors with experts in the field of water transport. The process of creating the cause and effect diagram was as follows:

- The final problem (effect) was defined very clearly;

- The final problem was put on the right and the causes were put on the left of the diagram;

- Each team member's understanding of the final issue was checked;

- The main categories of causes were laid as the main branches ("bones") of the diagram;

- Analysis of the main and secondary causes of the problem was conducted;

- The diagram was created.

As mentioned, the C\&E diagram consists of several main causes that ultimately contribute to an undesirable consequence (effect) - disruption of safe navigation. Every cause is identified and classified into one of six main categories (the diagram is simplified for readability; in fact, more than 70 causes affecting safe shipping have been identified and analysed), characterised in detail in the following sub-chapters.

\section{Manpower (Human Factor)}

The human factor is the cause of up to $90 \%$ of accidents in water transport (maritime and inland) [18]. The human factor is unpredictable given that each person has a different behaviour, perception, and understanding, but also level of ability to recognise danger and respond to it safely and effectively. Each person individually deals with workload or difficulties in everyday tasks. The following factors have a particular impact on human activities in the field of water transport:

- Operational experience;

- Human nature;

- Work environment;

- Work demands (organisation and management);

- Level of education, work structure;

- Information processes and communication;

- Fatigue, stress, time factors [19].

The human factor contains various aspects affecting human activity itself; in the case of water transport, this applies to ships' crew members and skippers. These aspects can be classified as follows:

Communication

The relevance, structure, and speed of information flow are very important elements when evaluating crises. Every single piece of information should be true and concise and have the shortest possible response. 


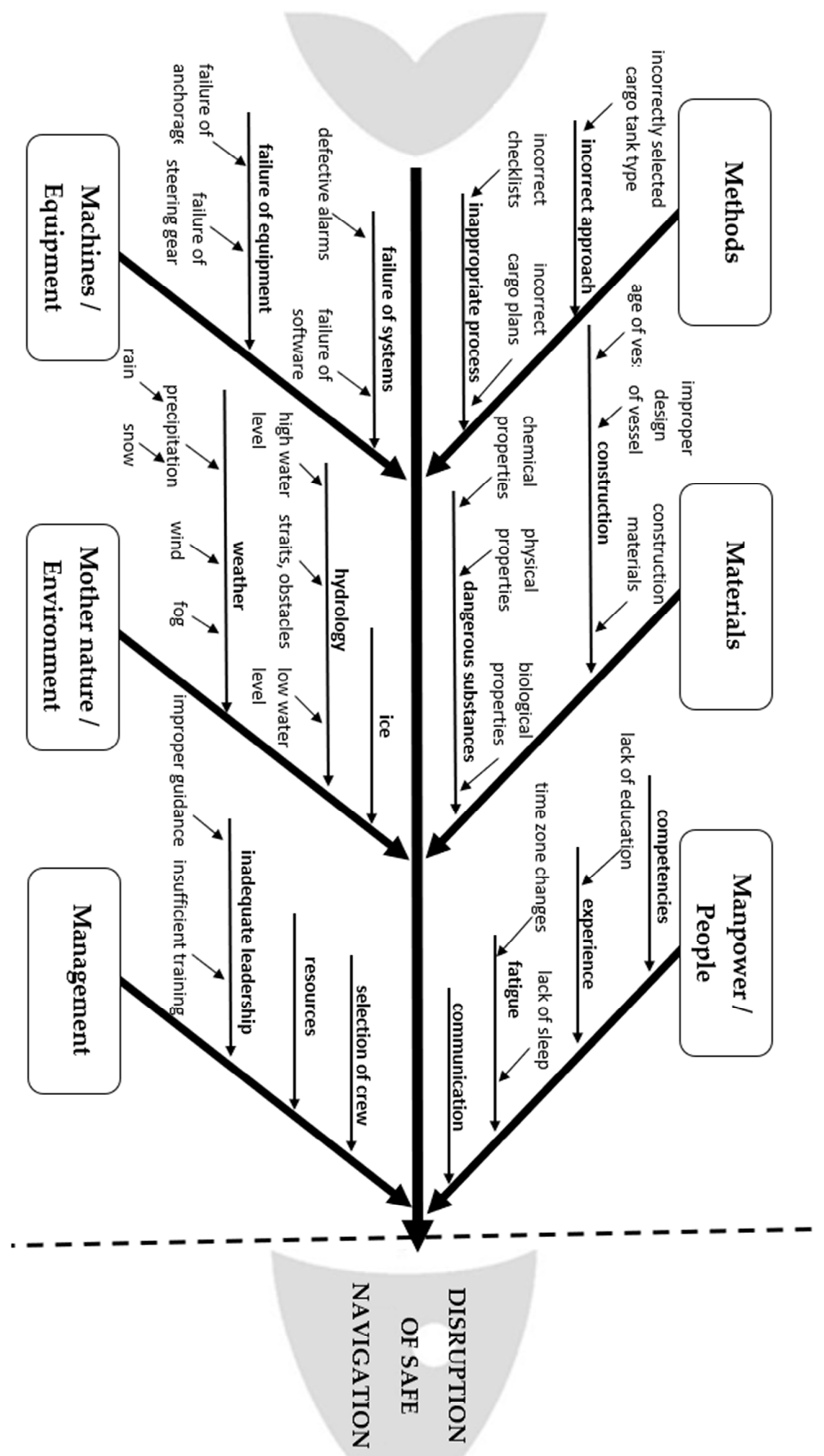

Figure 1. Cause and effect diagram applied to Danube navigation. 


\section{Operational experience}

Sufficient work experience and skills represent the most important background when a crisis occurs. For crew members with a lower number of hours worked, there is a greater risk of reckless (wrong) decisions than for experienced members who have more hours worked. The admission of a crew member is often determined by their practical experience in the field of water transport, which implies the irreplaceability of practical experience towards vocational training.

The process of communication includes the exchange of information between:

- Crew members;

- Operators and crew members;

- Information system and crew members.

Decision-making process

A decision-making process extremely influences the direction in which the situation will develop. This process is closely linked with the level of responsibility in a particular job position. Therefore, when making the decision, the skipper takes a greater risk than other crew members.

\section{Level of education}

Number of completed courses, completed levels of secondary and higher education, and obtained certificates or patents.

\section{Technical skills}

During navigation, the captain and crew members use various types of equipment (navigation devices, devices for mooring, manoeuvring, ballasting, or bunkering). Therefore, the technology on board, the machines, and the systems are in daily contact with the person who must control them and, above all, understand them. When working with equipment, people experience rapid moral wear and tear due to the impact of technological progress, which reduces the quality of work. Outdated equipment negatively affects the work ethic of all crew members. The impact of these secondary aspects determines the causes of accidents on a watercourse. The result in practice can be:

- Violation of navigation regulations (failure to respect distances, signs, warnings);

- Violation of cargo regulations (incorrect location, overload);

- Violation of regulations on the technical condition of the vessel (malfunctioning or damaged equipment, untruthfulness of information in the logbook);

- Incorrect assessment of the navigation situation (contact of the vessel with the bottom, grounding, collision) [18].

\section{Fatigue}

Fatigue can be defined in many ways - it can be a state of fatigue or drowsiness, which is the result of long-term mental or physical work, a period of anxiety, human exposure to a harsh environment, or insomnia or lack of sleep. The effects of fatigue are especially dangerous in the shipbuilding industry. The technical and specialised nature of this sector requires constant vigilance and intense concentration on the part of workers.

The ship's crew has been "trapped" in their work environment for a long time. The crew spends a long time away from home on a moving vessel, which is exposed to unpredictable environmental factors. There are often no clearly separated areas for work and rest on board. A limiting element is also the crew of people of different nationalities who are expected to live and work together [19]. The most common causes of fatigue on board are poor quality of rest, lack of sleep, stress, or excessive workload. There are many other factors that vary depending on these circumstances:

- Crew-specific factors (monotone work, workload, personal problems);

- Management factors (shift schedules, overtime, breaks; company culture and management style); 
- $\quad$ Environmental factors (high waves cause seasickness and sleep disorders).

Behaviour

Each person has an individual perception of reality, influencing the decision-making process. Inappropriate behaviour that leads to errors or violations can be categorised as intentional or unintentional.

The riskiest behaviour is when an individual voluntarily consumes alcohol or drugs during or before work. The presence of alcohol in the body has also been shown to increase the severity of injuries from accidents. Alcohol has a range of psycho-motor and cognitive effects that increase accident risk on reaction times, cognitive processing, coordination, vigilance, vision, and hearing, even at low blood alcohol levels.

Neglect of duty due to drug use is not the only behaviour defined as intentional risk behaviour. Moreover, sabotages and the possibility of enrichment at the expense of the vessel or owner are very risky types of behaviour (although these occur up to 10 times less often in inland navigation than in maritime navigation) [20]. Each person's behaviour is also very closely linked to their current state of health. In addition to the obvious adverse effects of stress and fatigue on a person's health, other variables may be behind the individual's risky behaviour. Hearing disorders can lead to serious mistakes, such as incorrect hearing of verbal orders. This can ultimately lead to misinterpretation of information or warnings being ignored, and finally to the wrong response to an emergency. A risky situation, such as an incorrect estimate of distance, is one of the symptoms of eye diseases. Colour blindness, myopia, and farsightedness are undesirable threats when working on a ship.

\section{Management}

To identify and analyse risks in Danube navigation, the management section was chosen over measurement, according to real shipping accidents analysed. Organisational factors relate to how vessels are managed and operated. These factors can potentially increase workload and cause stress that ultimately result in fatigue. These factors include:

- $\quad$ Role of shore personnel;

- Paperwork requirements;

- Economics;

- $\quad$ Shift schedules, overtime, breaks;

- Company culture and management style;

- Rules and regulations;

- Resources;

- Upkeep of vessel;

- Training and selection of crew.

Significant threats such as ill-chosen budgets (insufficient funds for repairs and maintenance, level of automation, etc.) and selection of human resources (insufficiently educated and trained staff) result from the decisions of resource management. Moreover, within a well-chosen management and control strategy, it is important to set up the organisational climate correctly. Organisational climate refers to the organisational structure (command, delegation, responsibility, communication channels, etc.), policies (promotion, sick leave, drugs, alcohol, accident investigations, overtime, etc.), and culture (unofficial rules, values, attitudes, and beliefs of an organisation).

Supervisory failure poses another major threat to management. Inadequate leadership includes providing inappropriate guidance, oversight, or training. Moreover, situations where supervisors fail to assess the risk associated with a task place the crew or operator at an unacceptable level of risk. Failure to correct known problem happens when the equipment, training, or behaviours, identified as unacceptable, remain uncorrected, meaning the supervisors fail to initiate corrective actions [21]. Supervisory violations represent cases when existing instructions, rules, or regulations are wilfully disregarded by those in positions of leadership, during their duties.

The quality of ships' crews and the quality of inland navigation are very much linked to the safety of traffic on waterways. A proper selection of employees (captain, crew, operators, 
shore personnel, and managers) is a very important element of safe navigation. Therefore, complying with transnational and national legislation in the field of technical equipment, vessel construction, and crew training represents a significant tool for increasing safe transportation. Likewise, the international STCW conventions (International Convention on Standards of Training, Certification and Watchkeeping) improve the safety of ship crews $[18,21,22]$. Shipping companies have realised the importance of proper human resources and have begun to pay more attention to this area in recent years.

\section{Methods}

Causes identified in this category represent inadequate performance of the process and improper or inadequate requirements for performing it, such as policies, procedures, rules, regulations, and laws. In terms of inland navigation, the failure of methods is represented by the incorrect compilation of the cargo plan (i.e., the cargo plan was not compiled according to the stability plan), errors in the checklist or forgetting to check an important item, errors between processes after the end of transport and before starting another transport (unventilated cargo space, routine shortcuts), undeclared dangerous goods, and improper procedures (mooring, anchorage, manoeuvring, labelling, etc.)

\section{Mother Nature (Environmental Factors)}

Environmental factors may include various impacts that adversely affect the voyage and thus reduce its effectiveness and safety. Environmental factors include the weather (influence of wind, fog, rain, etc.), and hydrological factors (water level, obstacles in the fairway, etc.)

\section{The weather}

The external effects are wind, current, and surface waves. All of them affect the stability of the direction and speed of the vessel. Adverse meteorological situations that usually affect navigation are:

- Wind-The movement of air mass that has a direction, speed, and density. The speed and density of the air create a continuous pressure on the superstructure, into which the wind rests with adequate force.

- Wind currents-Wind currents occur at the surface due to long-term exposure to wind. The friction of air against the surface also creates wind waves in the same direction as the current.

- Vortex-Vortices can occur in narrow straits of the ocean with fast-flowing water.

- Fog-Fog is caused by small droplets of atmospheric aerosols that reduce vertical and horizontal visibility. It has an impact on navigation safety mainly due to the decrease in visibility, which is important for risk-free navigation on the watercourse.

- Atmospheric precipitation, together with air temperature, is the most important meteorological and climatic element. Precipitation can be rain, snow, drizzle, frozen rain, hail, snow grains, or ice needles. From both a spatial and a temporal point of view, precipitation is one of the most variable meteorological elements. It is affected by the geographical location, altitude, or windiness of the area to the prevailing flow bringing moist air masses and frontal systems, and atmospheric precipitation is the product of the condensation or deposition of water vapor, which, in a liquid or solid state, falls from clouds to the earth's surface [23].

\section{Hydrological factors}

Hydrometeorological and hydrological conditions represent the sum of all properties that are characterised by the influence of the environment for a given stream. These are usually parameters such as average flow, water level, flow rate, volume or number of sediments entrained, wind force and speed at the surface, fog formation, temperature regime, and wave height. These parameters are usually influenced by ongoing activities in the atmosphere. Important conditions for the safety of navigation on a watercourse are as follows: 
- Creation of natural obstacles;

- Temperature and ice mode;

- Water status.

Natural obstacles

This factor is related to a particular waterway and its hydrological regime. In the riverbed, there are constant changes in the morphology and shape of the bottom due to the movement of sediments. Changes occur when the water level is low and high, or when the flow is increased, and they are permanent (straits, fords) or temporary (alluvium).

Temperature and ice mode

Ice phenomena occur when the ambient air temperature drops above the water surface. Ice phenomena temporarily cause limitations, in particular:

- Ice drift;

- $\quad$ Crushed ice;

- Stationary ice-continuous cover;

- Internal slurry.

The upper part of the surface first freezes, and stationary ice is formed. It does not pose a significant risk in the dense passage of the vessels, as the stationary ice is mixed and broken. With a lower voyage density, a thick, continuous layer of ice is formed, which paralyses the voyage. An internal ice slurry is formed on a river surface with a free surface, at a flow velocity of 0.6 to $1.0 \mathrm{~m} / \mathrm{s}$. At low temperatures and irregular sailing, ice accumulates. Ice drift is the most dangerous phenomenon in navigation, in which the formation of ice caps occurs; later, after breaking off, they are carried away by the current. Covers pose a dangerous risk to pressure kits and smaller vessels. The movement of icedrift - is influenced by wind and sea currents. Ice drift can exert enormous forces when it strikes structures and can cut rudders and propellers from ships and strong structures anchored ashore, such as piers. Ice can also affect navigation functionality [24].

Water level

The water level is defined as the height of the water level on the monitored watermark [24]. Obtaining information is important for vessels, mainly due to navigation restrictions. A low water level can cause fords or other obstacles in the flow. On the other hand, a high water level reduces the ground clearance of the underpasses of bodies seated in the fairway, such as pipes, power lines, or bridges.

\section{Machines/Equipment}

A fault is defined as a phenomenon in which the operational state of an object terminates or is interrupted. There are two common machine failure mechanisms:

- Human error-the failure occurs due to improper use or due to improper handling by the operating personnel;

- Nature of the material-the failure arises in connection with physical or chemical properties of the material from which the mechanism is made.

The most common failures of ships' equipment, resulting in navigation accidents, include failures of the steering, anchorage, and mooring equipment. Another significant step is to ensure proper protective equipment [25] for the crew, used in emergency situations or accidents.

\section{Failure of the steering gear}

A failure of the steering gear generally causes partial or complete loss of control of the vessel. A damaged vessel poses a threat to other vessels on the waterway because the nature of the watercourse causes unintentional vessel movements. Corrosion, cracks, and abrasive wear of the steering mechanisms can cause such failures. Deformation, breakage, or complete destruction of the rudder can occur due to mechanical force effects. 


\section{Failure of the anchorage equipment}

Anchorage failure poses a risk mainly due to the stable anchorage of the vessel on the waterway or at berth. When the anchor, anchor chain, or anchor winch fails, unintentional vessel movement may occur. Therefore, a moving vessel poses a threat if there is no crew on board. Corrosion and cracks occur on the parts of the anchorage system, causing fractures of the rope strands, untying, and fraying. Anchor chains may be subject to cracks, breakage, and abrasion of individual links, causing the chain or its attachments to break.

\section{Failure of mooring system}

Malfunction of the lashing device poses a danger during mooring of the vessel in the port, at a pontoon, at a pier, or on a waterway. Movement of the vessel towards the mooring element or quay can cause vessel crashes, and damage to the hull or other parts.

Intense corrosion and abrasion influence all parts of the lashing device. Then, this can result in untying, strapping, or breaking of the lashing ropes, loosening of the fastening screws, and deformation of pins and bushings [26].

Failure of the vessel's technical parts, equipment, and mechanisms is very difficult to prevent. It is almost impossible to inspect wear parts at regular intervals to prevent damage or destruction, especially on larger vessels. Proper material design is required, but the price is the main factor during repair. Therefore, expensive materials with better physical and chemical properties cannot be used over the present materials. For example, materials with better anti-corrosion properties, but that are equally strong and flexible, represent a much higher investment. Logically, the use of more expensive materials will be reflected in the final price of the vessel [26].

\section{Failure of navigation equipment}

The display of the navigation device (AIS, radar) may be insufficiently clear, its brightness may be poor, and the volume of the equipment may be low, with important warnings in this case being insufficient, and the displays may not be sufficient to warn the skipper of important events during the voyage. Navigation devices such as radar, sonar, AIS, GPS Inland ECDIS, and GNSS transmit the information necessary for navigation to the skipper of the vessel and thus increase the safety and efficiency of navigation. Errors in navigation devices can cause an emergency with unforeseen consequences, in particular:

- If the radar does not work properly, the skipper may lose track of obstacles on the waterway;

- If the sonar does not work, the vessel can collide with rocks or shallows;

- If the AIS device does not work, a collision of vessels can occur, especially when changing course;

- A loss of GNSS equipment could result in losing control of the vessel, and, subsequently, collision with obstacles can occur;

- If the ECDIS device does not display maps properly, an accident (collision) can occur $[27,28]$.

\section{Materials}

This category identifies causes related to materials and raw components. Shortage or faulty materials represent major causes in this case, e.g., improper vessel design, and use of defective materials (corrosive materials, abrasive materials). One specific type of goods represents the biggest risk for the transport process-dangerous goods. Dangerous goods are defined as substances or objects that may endanger human health and life or pollute the environment [29]. In this case, their physical, chemical, and biological properties are particularly dangerous, which can cause flammability, explosiveness, toxicity, spontaneous combustion, corrosivity, infection, or radioactivity.

Depending on the action of substances and materials, we can divide dangerous goods into two groups:

- Substances dangerous to human health-these may cause short- or long-term damage to health or even death if swallowed, inhaled, or absorbed through the skin; 
- Substances dangerous for the environment-in the case of leakage, they represent an immediate or later danger to the environment.

Dangerous goods with their hazardous properties (such as explosiveness, corrosiveness, toxicity, flammability, and radioactivity) are classified into nine classes:

1. Explosives (munitions, pyrotechnic materials);

2. Gases (oxygen, helium, cigarette lighters);

3. Flammable liquids (petroleum products, alcohol);

4. Flammable solids (matches, celluloid);

5. Substances liable to spontaneous combustion (phosphorus, fish meal);

6. Substances emitting flammable gases (with water) (metal powders);

7. Oxidising substances (hydrogen peroxide);

8. Organic peroxides (plastic adhesives);

9. Toxic substances (insecticides, pesticides);

10. Substances liable to cause infections (medical waste);

11. Radioactive material (uranium metal, nuclear fuel);

12. Corrosives (car batteries, sulphuric acid);

13. Miscellaneous dangerous substances (hazardous substances, mobile phones) $[29,30]$.

Even though the IWT of dangerous goods can pose a great risk, there is a necessity to realise that in every part of the supply chain there is a high probability of risk occurrence. All processes-manipulation, handling, transportation, and storage of hazardous substancesrequire high professionality, knowledge, skills, and experience. In fact, every single vessel (passenger, container, etc.) always carries dangerous goods in its fuel tanks.

The supply chain is not the only risk to the river environment and ecosystems. The topics of green supply chains and waste management have become significant topics to deal with. Therefore, in recent years, there have been heated discussions on these topics in IWT. As a result, several countries have adopted legislation related to waste management and reverse logistics. The EU has adopted Directive 2000/59/EC1 on port reception facilities for ship waste and cargo residues (hereinafter "the PRF Directive") to reverse this trend [25,31-35]. The goal the PRF Directive is "to reduce the discharge of ship-generated waste and cargo residues into the sea, especially unauthorised discharges, from ships using EU ports by improving accessibility, and use of port reception facilities".

The whole process of transportation of dangerous goods poses a great risk. Even though the risk is never zero, we can reduce it to the minimum. By taking preventive measures, we can eliminate the occurrence of emergency events that may endanger health and life, property, and the environment. It is necessary to pay attention to the strict regulations determined for individual modes of transport which will achieve a safe course of transport of dangerous goods.

\section{Summary}

The C\&E diagram was used for the identification of causal factors which caused the shipping accidents. Every causal factor (hazard) is classified into six categories. Therefore, the following table (Table 4) represents a comprehensive analysis of all real hazards influencing safe Danube navigation. 
Table 4. Causes of shipping accidents according to the cause and effect diagram classification.

\begin{tabular}{|c|c|}
\hline $\begin{array}{l}\text { CATEGORY } \\
\text { OF HAZARD }\end{array}$ & HAZARDS \\
\hline Manpower & $\begin{array}{l}\text { irresponsibility, negligence, fatigue, overconfidence, unprofessional work, breach of discipline, sabotage, } \\
\text { ignorance of regulations, poor health, bad mental state, stress, alcohol/drugs, improper communication (ship } \\
\text { to ship), missing skills/experience, poor education }\end{array}$ \\
\hline Management & $\begin{array}{l}\text { insufficient resources, inadequate training, inadequate crew selection, inadequate shift schedules, } \\
\text { underestimated inspections, inadequate maintenance, improper communication (shore to ship), wrong } \\
\text { coordination/guidance, improper oversight, lack of rescue equipment, missing documents, confusing orders, } \\
\text { failure of identification of an at-risk worker, failure of unsafe procedure report, } \\
\text { purchase of unsuitable equipment }\end{array}$ \\
\hline Materials & $\begin{array}{l}\text { improper vessel design, poorly designed equipment, use of defective materials, use of corrosive materials, use } \\
\text { of abrasive materials, weak ropes, dangerous goods transported, poor quality of material used for marking, } \\
\text { missing buoy, improper construction of tank, old safety equipment (extinguishers), poor seals }\end{array}$ \\
\hline Machines & $\begin{array}{l}\text { poor level of automation, unreliable equipment, design of equipment, failure of warning systems, failure of } \\
\text { safety devices, failure of hardware, failure of software, failure of navigation devices }\end{array}$ \\
\hline Methods & $\begin{array}{l}\text { cargo plan did not compile according to the stability plan, checklist error, unventilated cargo space, routine } \\
\text { shortcuts, improper use of equipment, undeclared dangerous goods, improper mooring procedures, improper } \\
\text { anchorage, improper manoeuvring, improper handling procedures, incorrect labelling procedures, } \\
\text { missing/broken visual signalling on ship, improper packing procedures, improper ballasting procedures, } \\
\text { improper bunkering procedures }\end{array}$ \\
\hline Mother Nature & $\begin{array}{l}\text { wind, wind currents, vortices, fog, precipitation (snow, rain, drizzle, frozen rail, snow grains,), ice drift, natural } \\
\text { obstacles, low water level, high water level }\end{array}$ \\
\hline
\end{tabular}

Source: Authors according to [36].

\subsection{Risk Matrix}

The process of risk assessment began with the identification of sources of risks, areas of impact, and events that may create risk, along with their causes and potential consequences. Using the C\&E diagram, hazards endangering safe shipping operations on the Danube River were identified. Those hazards led to real events and accidents that occurred on the Central Danube in the past several years. Based on the analysis of 185 accidents that occurred on the Danube in recent years, the most frequent hazards and risks were evaluated. For the process of risk assessment, the risk matrix was used-see Table 5. The risk matrix analyses and assesses the most common risks-accidents that occurred on the Danube in recent decades.

The risk analysis includes the process of sufficient understanding of identified risks to support downstream decision making. This process contains risk evaluation, the identification of consequences, risk likelihood, and proper hazard identification to remove, lessen, or manage negative effects. The purpose of risk evaluation is to provide a framework for making decisions on reducing the most significant hazards.

On the left side of the risk matrix, there are identified risks, based on the data collected and analysed (brainstorming with experts). In the middle of the risk matrix, the risk evaluation process is explained. Fourteen different risks were identified and placed inside the risk matrix. The right side of the matrix shows the causal factors (hazards) that led to the creation of each risk.

The aim of this research was to find out which factors cause emergencies and incidents leading to accidents in the conditions of the Danube navigation. In the period before the COVID-19 pandemic, increased cargo volumes caused more shipping accidents. This has logically jeopardised safe navigation. Based on the identification of the biggest hazards in inland navigation, risk reduction recommendations could be adopted. 
Table 5. Risk matrix.

\begin{tabular}{|c|c|c|c|c|}
\hline \multirow[t]{2}{*}{ RISK } & \multicolumn{3}{|c|}{$\begin{array}{c}\text { INHERENT RISK } \\
1 \text { = Low/Acceptable, } \\
5=\text { High/Unacceptable }\end{array}$} & \multirow{2}{*}{$\begin{array}{l}\text { HAZARDS } \\
\text { That Led to Risk } \\
\text { (Real Accidents) }\end{array}$} \\
\hline & L (1-5) & C (1-5) & $\begin{array}{l}\text { Inherent Risk } \\
(\mathrm{L} \times \mathrm{C})\end{array}$ & \\
\hline $\begin{array}{l}\text { leakage of a dangerous substance } \\
\text { (less than 100l) }\end{array}$ & 2 & 2 & 4 & $\begin{array}{l}\text { irresponsibility, negligence, } \\
\text { unprofessional work, alcohol, missing training }\end{array}$ \\
\hline environmental accident & 2 & 5 & 10 & $\begin{array}{l}\text { negligence, alcohol, missing training, improper bunkering procedures, } \\
\text { inadequate crew selection }\end{array}$ \\
\hline fire & 2 & 5 & 10 & $\begin{array}{l}\text { sabotage, health, unventilated cargo space, routine shortcuts, improper use } \\
\text { of equipment, undeclared dangerous goods, inadequate crew selection, } \\
\text { inadequate maintenance }\end{array}$ \\
\hline collision with a bridge & 3 & 3 & 9 & $\begin{array}{l}\text { precipitation, high water level, fatigue, unprofessional work, stress, alcohol, } \\
\text { missing skills, improper manoeuvring, inadequate shift schedules, } \\
\text { missing buoy }\end{array}$ \\
\hline collision in the lock chamber & 2 & 3 & 6 & $\begin{array}{c}\text { irresponsibility, negligence, fatigue, improper communication (shore to ship), } \\
\text { improper mooring procedures, wrong coordination, confusing orders, } \\
\text { failure of unsafe procedure report, } \\
\text { failure of software, broken visual signalling on ship }\end{array}$ \\
\hline collision with the port facilities & 2 & 3 & 6 & $\begin{array}{l}\text { irresponsibility, negligence, fatigue, alcohol, improper communication (shore } \\
\text { to ship), improper mooring procedures, confusing orders, } \\
\text { failure of software, broken visual signalling on ship }\end{array}$ \\
\hline collision with another vessel & 2 & 4 & 8 & $\begin{array}{l}\text { irresponsibility, negligence, fatigue, alcohol, incorrect communication (ship } \\
\text { to ship), incorrect mooring procedures, } \\
\text { software failure, wind, precipitation, waves, fog }\end{array}$ \\
\hline grounding & 3 & 3 & 9 & $\begin{array}{l}\text { negligence, fatigue, overestimation of abilities, drugs, alcohol, poor } \\
\text { communication (ship-shore and vice versa), ice, low water level }\end{array}$ \\
\hline cargo handling accident & 1 & 5 & 5 & $\begin{array}{l}\text { irresponsibility, negligence, fatigue, overconfidence, unprofessional work, } \\
\text { bad health, drugs, alcohol, routine shortcuts, improper use of equipment, } \\
\text { poor level of automation, failure of warning systems }\end{array}$ \\
\hline $\begin{array}{c}\text { accident during } \\
\text { embarking/disembarking }\end{array}$ & 3 & 3 & 9 & $\begin{array}{l}\text { negligence, fatigue, ignorance of regulations, alcohol, drugs, use of defective } \\
\text { materials, use of corrosive materials, poor material used for marking, wind }\end{array}$ \\
\hline man overboard & 2 & 4 & 8 & $\begin{array}{l}\text { alcohol, drugs, negligence, fatigue, overconfidence, poor mental state, weak } \\
\text { materials (railings, deck), sabotage }\end{array}$ \\
\hline delay of navigation & 2 & 1 & 2 & $\begin{array}{l}\text { routine shortcuts, power failure, equipment malfunction, alcohol, high/low } \\
\text { water level, fog, precipitation, ice, wind }\end{array}$ \\
\hline hull damage & 2 & 3 & 6 & $\begin{array}{l}\text { negligence, fatigue, overestimation of abilities, drugs, alcohol, poor } \\
\text { communication (ship-shore and vice versa) }\end{array}$ \\
\hline sinking of vessel & 2 & 5 & 10 & $\begin{array}{l}\text { cargo plan does not compile according to the stability plan, bad mental state, } \\
\text { stress, improper use of equipment }\end{array}$ \\
\hline
\end{tabular}

Source: Authors according to [36]; L: Likelihood; C: Consequences.

\section{Recommendations}

Considering the above facts, it is crucial for the EU states with access to important waterways to take immediate steps to mitigate the number of shipping accidents. This step ensures saving human lives, the environment, and assets. Based on the research, the following recommendations for the development of waterway safety are proposed:

\section{(1) To include information into RIS's subsections.}

River Information Services (RIS) are harmonised information services to support traffic and transport management in inland navigation, including interfaces with other transport modes. RIS are expected to improve safety, efficiency, and the environmental friendliness of inland navigation. The EU has taken a global approach that encompasses policy development, a legal framework, support for research and development, and monitoring of implementation of the legislation [31,37].

There are four key technologies within RIS: Inland Electronic Chart Display and Information Systems (Inland ECDISs), Notices to Skippers (NtS), Inland AISs, and Electronic Reporting International (ERI). These technologies are based on technical and operational standards, defined and continuously updated by the RIS Expert Groups [31]. The RIS Directive demands member states to implement RIS according to these standards. However, not all EU member states have developed and established functions of individual elements at the same level. The Slovak RIS system (SlovRIS) consists of the named components. The authors propose the following suggestions for improving the system by enhancing each component: 


\section{(a) Inclusion of ford information}

Based on the research of causal factors on the Danube (river kilometre: 1880.26-1718.20), it was revealed that the narrow sections involve fords, especially in the following locations (river kilometres):

- 1878;

- 1863.9-1865;

- 1867 ;

- $1861 ;$

- 1870.5-1871.4 [37].

The section Notices to Skippers does not sufficiently inform skippers about current ford locations-these are not displayed by the radar display or in electronic charts. Fords and straits are often not marked with red buoys (cause: higher water-a strong current can tear off the buoy).

The Slovak Water Management Enterprise, a state enterprise (waterway administrator in the conditions of the Slovak Republic), provides information on the current state of fords and straits and regularly provides information on water levels, flow, and fords (dispatching by 6:00 a.m.). However, this information is no longer provided to skippers and is not published on the SlovRIS website. If skippers want to be informed about fords, they must request a dispatcher for information via radio.

For this reason, we propose introducing additional ford information (within the "ford section") with the current date and time, and forecasts for the next $24 \mathrm{~h}$. These data could be displayed within the electronic map.

\section{(b) Inclusion of ford information}

The change in the water level affects the vertical clearance under bridges. The total length of the Slovak part of the Danube is 172 kilometres (the Slovak section begins at the river kilometre 1880.26). When investigating shipping accidents, we focused on the section 1880-1853, as there are five bridges in this section. The SlovRIS system provides information on the location of bridges, and underpass height and width. However, the system does not provide information about changed clearance under the bridge, caused by a drop/rise in the water level. We propose including information about changes in the vertical clearance within the subsection "Information on the fairway", with forecasts for the next $24 \mathrm{~h}$. The information may be provided by sending GPS corrections from the shore segment to ships. The transmission of water level data was tested in the IRIS II project, but after the end of the project, the transmission of data was terminated [37].

\section{(c) Inclusion of ford information}

Ice phenomena usually form from November to March. Ice data are provided to skippers through reports. Vessels sailing from the Upper Danube (Germany, Austria), or in the opposite direction, should be informed about bad ice situations to avoid the accumulation of vessels, the blocking of navigation, and its delay. In the case of ice occurrence, the hull of the vessel can be damaged, and oil substances can leak into the waterway. With a permanent ice cover of the water surface, it is more difficult to remove oil products from the stream. Therefore, we propose including the ice information within the "Fairway information section", together with restrictions of navigation.

\section{(d) Inclusion of ford information}

Calamity Abatement Support (CAS) represents one of the RIS services (ERI subsystem service). The application has been developed for the exchange of information on inland waterway accidents, ensuring compatibility between all European countries. The application was involved in the IRIS Europe project. After "activating" an accident in the system, authorised persons can use the information about the accident when planning the intervention. The system provides the following: 
- The creation of accident notifications by the Transport Authority, which receives the initial information about the accident and subsequently informs the other components; - The sending and receiving of accident notifications to and from neighbouring countries or users requesting accident information;

- Storage of accident notifications in a database, including message history;

- Administration of users authorised to receive accident information [37].

If an accident occurs, the staff of the Transport Authority (State Professional Supervision Section) and the Dispatching Office can provide information on the vessel and cargo immediately. Such information helps to reduce the time needed to deal with the consequences of an accident and increases the coordination of rescue forces. After notification of the accident to the skipper or a crew member, the CAS form is filled in by an employee of the Transport Authority (State Professional Supervision). This form also informs the integrated rescue system about the accident, as well as other authorities: environmental inspectors, civil protection workers, etc. [37].

Currently, the system does not inform any of the IRS parties or other authorities. The reason for not using such a comprehensive emergency reporting system is simple-legal obstacles. GDPR data and confidential information are not allowed to be provided to emergency service providers (position of vessels, cargo transported, etc.). For this reason, the level of information provided to rescue services is not sufficient for rescue operations. The lack of a communication interface between RIS infrastructures and emergency service provider systems represents another failure.

Despite the existence and apparent non-use of the CAS system, it is important to note that, according to expert interviews with members of the fire brigade, $99 \%$ of accidents on the Danube are not reported by ship managers or Dispatching Office staff, but by accidental passers-by who witnessed the accident. In the event of an emergency, dispatching employees (Bratislava Transport Authority-Inland Navigation Division) can evaluate the type of event and will be able to inform the rescue services and all authorities whose presence is necessary for the intervention. As the form cannot be completed by the skipper, who oversees the elimination of negative consequences of the accident, we propose filling in the information of the CAS reports automatically, using data from the Vessel Register. After entering the name of the vessel in the CAS form, the vessel and voyage data would be filled in automatically to speed up the notification of the rescue services that appear for each vessel registered in the Vessel Register.

\section{(2) To install navigational aids in the case of bad meteorological situations}

Most significant extreme weather events result from high precipitation, droughts, and temperatures below zero degrees Celsius. Heavy rainfall may lead to floods, resulting in suspension of navigation, and can cause damage to the infrastructure on waterways. Long periods of drought may lead to low water levels, limiting the cargo-carrying capacity of vessels and increasing the transport costs. Temperatures below zero degrees Celsius lasting a longer period may cause the appearance of ice on waterways, leading to suspension of navigation and possible damage to infrastructure (buoys).

The data covering the period 2000-2020 show the accident accumulation points as sections with a high traffic density such as locks, bridges, and curves, occurring when there are higher water levels [36]. The most common types of accidents are collisions with objects, infrastructure (bridges), and vessels as well as grounding. About $72 \%$ of all shipping accidents were caused by human error. Only $11.5 \%$ of accidents were caused by a bad weather situation.

The temperature is the main element influencing the meteorological stage. The influence of strong wind can be so serious that the vessel may lose its manoeuvrability; however, still, in the majority of cases, it only causes negligible material damage. In adverse meteorological situations, reduced visibility occurs, influencing the observation of bridge teams. The reduced visibility results from the cloudiness, precipitation, fog, influence of the ice flow, etc. 
To reduce accidents that occur because of reduced visibility, sound signalisation should be used. The siren, horn, and searchlight of ships should be checked regularly to perform their actions effectively. A sufficient number of navigational aids (marks and buoys) and signs should be installed on the crisis locations of fairways for both day and night navigation [38].

Virtual Aids to Navigation (AtoNs)

AtoNs are defined by IALA as a device or system external to vessels designed and operated to enhance the safe and efficient navigation of vessels and/or vessel traffic [38]. The main purpose of AtoNs is to help skippers and captains determine their position, follow a safe course, and avoid obstructions.

The concept of virtual AtoNs is presently implemented using automatic identification system (AIS) radio technology viewable on the bridge where AtoNs can be projected to locations where no physical AtoN exists. AtoNs may also be included within electronic charts and displayed using ECDISs (Electronic Chart Display and Information Systems).

The ability to provide virtual AIS AtoNs is one of the most significant technical developments for service providers but is only possible through the deployment of a network of AIS base stations around the coast/along the waterways and, most importantly, the installation of onboard equipment that has the capability of decoding and displaying the data; typically, these are Application Specific Messages relating to virtual aids to navigation in an "AtoN Report". These messages provide details of the name, MMSI, type, and position of the AtoN [39].

\section{(3) Proper vessel design and regular checks of vessel}

To prevent overloading the cargo vessel's capacity, random inspections should be performed (to compare if cargo manifest information fits with the real state). For passenger vessels, passenger counting systems should be adopted.

For the reduction in accidents related to stability failure, there is a necessity for proper vessel design during the building process. This procedure should be performed by a skilled expert on a ship design. Then, once the vessel is in regular service, the capability of the vessel should be checked on a regular basis.

\section{(4) To organise regular training for the crew members}

Accidents resulting from insufficient training of crew members represented almost 17\% of all shipping accidents between 2000 and 2020 on the Danube. Proper and regular training can significantly improve job performance by increasing individual abilities, stimulating motivation, and/or matching the individual to contextual requirements. Currently, there is a poor quality of training for the crew members of inland vessels. For this purpose, the European Commission has set in motion a sweeping modernisation of the applicable rules. Their approach is based on precisely defined competences enabling the creation of a system of harmonised professional qualifications within the EU. The standards lay down details of a new competence-based approach for deck crew members.

\section{(5) Reducing bad working habits and fatigue onboard}

Provisions of Act no. 462/2007 on the organisation of working time in transport establish the working time and rest time of employees in water transport of the Slovak Republic. This law defines the daily working time so that it does not exceed:

- Fourteen hours for twenty-four consecutive hours;

- A weekly working time of $84 \mathrm{~h}$;

- A weekly night working time of $42 \mathrm{~h}$.

The research of shipping accidents caused by fatigue revealed several violations of the law (employees did not respect the time of night work during the working week and the maximum working time for 24 consecutive hours). Mandatory breaks were also not respected (continuous daily rest for at least 6 consecutive hours if the total rest period is at least 10 hours for 24 consecutive hours). 
If one crew member consumes alcohol and cannot perform the work properly, and another colleague takes his shift (even when he should rest in this period), the problem of fatigue and insufficient rest arises. The working and rest times of crew members are extremely difficult to check. The development of devices that can detect an employee on their working position during work is a very important idea to be implemented into the transport process to ensure safety increases and bad habits and fatigue decrease.

\section{Conclusions}

The Danube River plays a strategic role within the pan-European transport network. This international river, connecting Central Europe with major economic areas in Western Europe and the Black Sea region, represents a backbone of the continent. Danube navigation offers many advantages (if we compare it with conventional transport modes), such as the ability to convey large quantities of goods per vessel unit, low transport costs, and environmental friendliness.

Despite all the benefits that inland waterway transport offers, risks remain an everyday part of life, and the risk level will never be zero.

Danube accident research shows that many factors influence safe inland navigation. Environmental factors including the weather and hydrological conditions (ice, high or low water level) partly contribute to accident occurrence on the waterway. On the other hand, the human factor represents the most harmful element in the safety of inland navigation. Fatigue and stress are the main factors behind accidents caused by the unintentional behaviour of humans. Repetitive causal factors (hazards) resulting in risk confirm that the human factor is one of the crucial factors when incidents turn into accidents (72\% of all accidents occurred because of harmful human behaviour). The remaining $28 \%$ of accidents occurred because of bad weather conditions, insufficient information provided within the RIS system, and improper vessel design (construction).

Other important factors influencing safe navigation are the hazardous properties of dangerous substances, and the maintenance and construction of the vessel. However, there is another significant threat affecting transport efficiency in particular these days. The threat of the COVID-19 pandemic has affected and devastated the world economy. It is evident that the COVID-19 crisis is harmful mainly for the sector of tourism, passenger transport, and the service sector in general.

The results of this study highlight the importance of proper crew member training, and compliance with national regulations determining maximal working and resting periods, hours, and breaks in accordance with national regulations laying down guidelines for crew members, and the necessity of proper vessel design and regular checks. This study also provides comprehensive recommendations for improving the Slovak RIS system, which ensures a crucial improvement in the safety of Slovak water transport. Moreover, recommendations on virtual AtoNs are provided, as these systems provide a near-instantaneous warning to the captain or skipper of a new danger (such as a wreck, obstruction, or floating debris).

Author Contributions: Conceptualisation, M.M.; data curation, M.M. and A.D.; formal analysis, M.M.; investigation, A.D.; methodology, Andrea Maternová; project administration, A.M. and M.M.; resources, A.D.; supervision, A.M.; visualisation, A.M. and M.M.; writing—original draft, A.M. All authors have read and agreed to the published version of the manuscript.

Funding: This research received no external funding.

Institutional Review Board Statement: Not applicable.

Informed Consent Statement: Not applicable.

Data Availability Statement: Not applicable.

Acknowledgments: This publication was created thanks to support under the Operational Program Integrated Infrastructure for the project: Identification and possibilities of implementation of new techno- 
logical measures in transport to achieve safe mobility during a pandemic caused by COVID-19 (ITMS code: 313011AUX5), co-financed by the European Regional Development Fund.

Conflicts of Interest: The authors declare no conflict of interest.

\section{References}

1. David, A.; Madudova, M. The Danube river and its importance on the Danube countries in cargo transport. Transp. Res. Procedia 2019, 40, 1010-1016. [CrossRef]

2. Nedea, P.S.; Milea, O.M.; Pascu, E. The importance of Danube river as strategic navigation corridor. Constanta Marit. Univ. Ann. 2012, 16, 97-102.

3. Hartl, T.A.; Hofbauer, V.B. Manual on Danube Navigation; Via Donau: Vienna, Austria, 2013; Volume 3, pp. 16-24.

4. Zhang, D.; Yan, X.; Yang, Z.; Wang, J. An accident data-based approach for congestion risk assessment of inland waterways: A Yangtze River case. Proc. Inst. Mech. Eng. Part O J. Risk Reliab. 2013, 228, 176-188. [CrossRef]

5. Vidan, P.; Grządziela, A.; Bošnjak, R. Proposal of Measures for Increasing the Safety Level of Inland Navigation. Trans. Marit. Sci. 2012, 1, 85-88. [CrossRef]

6. Galieriková, A.; Sosedová, J. Environmental aspects of transport in the context of development of inland navigation. Ekológia-SAV (Bratislava) 2016, 35, 279-288. [CrossRef]

7. Uddin, I.; Islam, M.R.; Ibn Awal, Z.; Newaz, K.M.S. An Analysis of Accidents in the Inland Waterways of Bangladesh: Lessons from a Decade (2005-2015). Procedia Eng. 2017, 194, 291-297. [CrossRef]

8. Sun, L.; Zhang, H.; Liu, W.; Chen, F. Research on risk assessment and control of inland navigation safety. Int. J. Syst. Assur. Eng. Manag. 2017, 9, 729-738. [CrossRef]

9. Yu, Y.; Chen, L.; Shu, Y.; Zhu, W. Evaluation model and management strategy for reducing pollution caused by ship collision in coastal waters. Ocean Coast. Manag. 2021, 203, 105446. [CrossRef]

10. Liu, K.; Yu, Q.; Yuan, Z.; Yang, Z.; Shu, Y. A systematic analysis for maritime accidents causation in Chinese coastal waters using machine learning approaches. Ocean Coast. Manag. 2021, 213, 105859. [CrossRef]

11. Yan, T.; Qian, D.; Shu, Y.; Yang, Y.; Xu, R. Vessel navigation risk and stern-swing index in sharp bend channels. Ocean Eng. 2021, 238, 109640. [CrossRef]

12. European Commission. Study on Rhine-Danube TEN-T Core Network Corridor, 2nd Phase, Final Report. Available online: https:/ / ec.europa.eu/transport/sites/transport/files/rhd_study_2017_final_report.pdf (accessed on 1 January 2022).

13. Danube Region Strategy, Institutional Capacity. Publications of Eusdr Priority Area 10 "Institutional Capacities \& Cooperation". Available online: https:/ / capacitycooperation.danube-region.eu/documents/ (accessed on 1 January 2022).

14. Park, J.; Nam, G.; Choi, J. Parameters in cause and effect diagram for uncertainty evaluation. Accreditation Qual. Assur. 2011, 16, 325-326. [CrossRef]

15. Liliana, L. A new model of Ishikawa diagram for quality assessment. IOP Conf. Series Mater. Sci. Eng. 2016, 161, 012099. [CrossRef]

16. Simmons, D.C.; Dauwe, R.; Gowland, R.; Gyenes, Z.; King, A.G.; Riedstra, D.; Schneiderbauer, S. Understanding Disaster Risk: Risk Assessment Methodologies and Examples. In Qualitative and Quantitative Approaches to Risk Assessment; European Union-DRMKC Centre: Brussels, Belgium, 2017; Volume 2, 94p.

17. Markowski, A.S.; Mannan, M.S. Fuzzy risk matrix. J. Hazard. Mater. 2008, 159, 152-157. [CrossRef] [PubMed]

18. Galieriková, A. The human factor and maritime safety. Transp. Res. Procedia 2019, 40, 1319-1326. [CrossRef]

19. Turcan, R. Plavebne Nehody vo Vnutrozemskej Plavbe. Master's Thesis, University of Zilina, Zilina, Slovakia, 2017.

20. Galierikova, A.; David, A.; Sosedova, J. Fatigue in maritime transport. ASEJ Sci. J. Bielsk.-Biała Sch. Financ. Law 2020, 24, 35-38. [CrossRef]

21. Vidan, P.; Kasum, J.; Mitrovic, F. Improving the Quality of Inland Crew. Ships Inland Waterw. 2012, 6, 163-176.

22. Galieriková, A.; Materna, M. World Seaborne Trade with Oil: One of Main Cause for Oil Spills? Transp. Res. Procedia 2020, 44, 297-304. [CrossRef]

23. Cornish, M.; Ives, E. Reeds Maritime Meteorology, 1st ed.; Bloomsbury: New York, NY, USA, 2006; 264p.

24. Slesinger, J. Plavebna Nauka; EDIS, Publisher of University of Zilina: Zilina, Slovakia, 2013; 183p.

25. Yang, Y.; Wang, Y. Supplier Selection for the Adoption of Green Innovation in Sustainable Supply Chain Management Practices: A Case of the Chinese Textile Manufacturing Industry. Processes 2020, 8, 717. [CrossRef]

26. Klepoch, J.; Kalina, T.; Jurkovic, M.; Piala, P. Teoria Lode, 1st ed.; EDIS, Publisher of University of Zilina: Zilina, Slovakia, 2018; $296 \mathrm{p}$.

27. Turiak, M.; Sedláčková, A.N.; Novak, A. Portable Electronic Devices on Board of Airplanes and Their Safety Impact; Springer: Berlin/Heidelberg, Germany, 2014; pp. 29-37. [CrossRef]

28. Zacik, N.; Novak, A. Passive Radar System for Slovakia. In Proceedings of the 3rd International Conference on Traffic and Transport Engineering (ICTTE), Belgrade, Serbia, 24-25 November 2016; pp. 31-35.

29. United Nations. European Agreement Concerning the International Carriage of Dangerous Goods by Inland Waterways (ADN); United Nations: Geneva, Switzerland, 2000.

30. United Nations. Recommendations on the Transport of Dangerous Goods-Model Regulations, 21st Revised ed.; United Nations: New York, NY, USA, 2019. 
31. European Parliament and Council. Directive 2005/44/EC of 7 September 2005 on Harmonised River Information Services (RIS) on Inland Waterways in the Community. Consolidated Version. 2005. Available online: https:/ / eur-lex.europa.eu/legal-content/ EN/TXT/?uri=CELEX\%3A02005L0044-20190726 (accessed on 1 January 2022).

32. Vieira, B.; Guarnieri, P.; Nofal, R.; Nofal, B. Multi-Criteria Methods Applied in the Studies of Barriers Identified in the Implementation of Reverse Logistics of E-Waste: A Research Agenda. Logistics 2020, 4, 11. [CrossRef]

33. Mohtashami, Z.; Aghsami, A.; Jolai, F. A green closed loop supply chain design using queuing system for reducing environmental impact and energy consumption. J. Clean. Prod. 2020, 242, 118452. [CrossRef]

34. Touboulic, A.; McCarthy, L.; Matthews, L. Re-imagining supply chain challenges through critical engaged research. J. Supply Chain Manag. 2020, 56, 36-51. [CrossRef]

35. Galieriková, A. Inovatívne Spôsoby Monitorovania Prepráv Nebezpečného Nákladu na Dunaji. (Inovative Ways of Monitoring the Dangerous Goods Transportation on the Danube). Ph.D. Thesis, EDIS-University of Zilina, Zilina, Slovakia, 2018. Available online: http:/ / opac.crzp.sk/?fn=detailBiblioForm\&sid=5405D7E2C43D9DAFB699C4CA0676\&seo=CRZP-detail-kniha (accessed on 1 January 2022).

36. Transport Authority. Data Based on Consultation, Brainstorming and Research Activities, Brainstorming and Research Activities. 2021; Unpublished work.

37. Chalupka, S. Riečne informačné služby na Slovensku (River Information System in Slovak Republic); Slovak Shipping Days: Bratislava, Slovakia, 2013; 12p, manuscript in press.

38. IALA. Aids to Navigation. Report. Available online: www.navcen.uscg.gov/pdf/AIS/ITU-R_M1371-3AISMsg_21.pdf (accessed on 1 January 2022).

39. Wright, R.G.; Baldauf, M. Virtual Electronic Aids to Navigation for Remote and Ecologically Sensitive Regions. J. Navig. 2016, 70, 225-241. [CrossRef] 